\title{
Data Control and Surveillance in the Global TB Response: A Human Rights Analysis
}

\author{
Kat Albrecht and Brian Citro \\ Northwestern University and Northwestern Pritzker School of Law, United States
}

\begin{abstract}
The global response to the tuberculosis (TB) epidemic is generating copious amounts of personal health data. The emerging emphasis on the use of active case finding and digital adherence technologies in the TB response will increase the amount and expand the kind of data produced and used by public and private health officials. The production of personal data in high TB burden countries, in particular, must be considered in light of their colonial histories. In doing so, we argue that interventions to eliminate TB at global and national levels are ushering in a new era of data colonisation and surveillance in the name of public health. This, in turn, raises critical concerns for the human rights of people affected by TB, many of whom belong to vulnerable or marginalised groups. We examine the normative and legal content for a set of international human rights critical to the TB response, highlighting how each right implicates the production and use of personal health data. We also demonstrate that these rights are, by and large, enshrined in the constitutions of each high TB burden country. Finally, we use these rights to analyse active case finding and digital adherence technologies to pinpoint their unique data risks and the threats they pose to the human rights of people affected by TB.
\end{abstract}

Keywords: Neocolonialism; data vulnerable; tuberculosis; human rights.

\section{Introduction}

In the digital age, more data is accessible than ever before. This data has allowed us to innovate, connect and predict things that have historically been impossible on a large scale. While the field of mass data generation has been undulated with praise, critics have also begun to highlight the consequences and costs of handling data privacy and storage both for organisations and individuals. ${ }^{1}$ A growing literature has begun recognising the larger meanings of ethics and data privacy, commodifying data for sale and ownership, data for market research and data transparency and consent. This creates a complex new terrain where differing interests in the new data economy are weighed against each other. Much like data collection and traditional public health measures, this requires a sort of balancing act between the individual and public interest, which logically extends to balancing individual and institutional power. ${ }^{2}$ Exemplifying the ethical quandary of the mass data era are the questions of who actually owns personal data and how that data changes the social landscape. ${ }^{3}$ Some scholars argue that individual data should be treated as labour, the possession of users that should primarily benefit their owners, and not capital to be collected by firms as 'exhaust' from online consumption. ${ }^{4}$ However, these arguments tend to focus on individuals as consumers and voluntary participators in the Western world of data. Data applications in the modern world have broader consequences when applied to institutional control of particularly sensitive data about less voluntary participants. When it comes to personal health data and infectious disease among more vulnerable populations: do people own their own data? What does ownership mean in the

\footnotetext{
${ }^{1}$ Tallon, "Corporate Governance of Big Data," 32.

2 Kaplan, "How Should Health Data be Used," 313.

${ }^{3}$ Davis, Ethics of Big Data.

${ }^{4}$ Arrieta-Ibarra, "Should We Treat Data as Labor," 38.
} 
context of public health, when governments have a legitimate interest in personal health data? Can we truly protect vulnerable groups from the negative externalities of public health surveillance with existing data security protocols and privacy protections?

These questions become particularly important in the face of one the most devastating, stigmatised and enduring diseases in the modern world. The tuberculosis (TB) epidemic continues to affect countries all over world, killing more people per year than any other infectious disease. ${ }^{5}$ Over 10 million people per year become sick from TB, and some studies estimate that onequarter of people in the world have the TB infection. ${ }^{6}$ In India, an estimated 354 million people have latent TB that could transition into active TB disease. ${ }^{7}$ Importantly, the burden of TB is not felt equally across the world. The highest burden TB countries identified by the World Health Organization (WHO) cluster in India and sub-Saharan Africa, and TB disproportionately afflicts vulnerable groups who suffer from a myriad of other illnesses and social and economic disadvantages. ${ }^{8}$

As governmental and non-governmental agencies implement TB prevention, diagnosis and treatment programmes, they are simultaneously producing large amounts of data about people affected by TB. The generation of data and the subsequent surveillance of these geographies is not new, as research has demonstrated by extending colonialism metaphors to underlying data commodification of individuals in postcolonial contexts around the world. ${ }^{9}$ We investigate this data postcolonialism through two key parts of the global TB response - active case finding (ACF) and digital adherence technologies (DATs) — to understand and examine how human rights can be violated through data collection, control and commodification. We then analyse ACF and DATs to illuminate their inherent data risks and the threats they pose to the human rights of people affected by TB.

\section{Vulnerable Groups in the Big Data Economy}

Despite the supposed objectivity of data en masse, big data is vulnerable to errors, it can be inflexible, and it has the potential to discriminate. ${ }^{10}$ There are a variety of risks inherent to data storage and use, in that 'transparency, flexibility, and accountability are needed for assessing appropriate, judicious, and ethical data uses and users, as some are more compatible with societal norms and values than others'. ${ }^{11}$ While concerns about data are likely to be amplified in the increasingly digital future, including through the industrial application of artificial intelligence, we have robust historical evidence that data can be used to the disadvantage of individuals and groups. In the United States, data has been used to unfairly discriminate against certain groups of people when it comes to obtaining credit, employment and housing. ${ }^{12}$ A White House review confirmed that big data can be used in this way, not just by businesses but also by government agencies. ${ }^{13}$ This demonstrates that the wide spectrum of data stakeholders - in private and public sectors - have the potential to adversely affect individuals.

We also already know that private citizens are particularly concerned about data use in health contexts. A study by Lofters et al. found that nearly half of adults in the United States do not think hospitals should even collect individual-level sociodemographic data for fear of discrimination. ${ }^{14}$ Even when data is originally tracked by the patient, research shows that the data has been used for other purposes by researchers, governments and other actors. ${ }^{15}$ Lofters et al. reports that fear of data misuse was particularly salient among those who had previously experienced some form of discrimination or belonged to a minority group. ${ }^{16}$ Indeed, we have historic and contemporary examples of these fears being realised. For example, people living with HIV have long experienced stigma and discrimination as a result of breaches to their personal health data. ${ }^{17}$ Courts around

\footnotetext{
${ }^{5}$ WHO, Global Tuberculosis Report.

${ }^{6}$ Cohen, "The Global Prevalence of Latent Tuberculosis," 8; WHO, Global Tuberculosis Report.

${ }^{7}$ Moonan, "Tuberculosis Preventative Treatment," 1.

${ }^{8}$ WHO, Global Tuberculosis Report, 23.

9 Thatcher, "Data Colonialism Through Accumulation by Dispossession," 990.

${ }^{10}$ Crawford, "Critiquing Big Data," 1668.

${ }^{11}$ Kaplan, "How Should Health Data be Used," 312.

${ }^{12}$ Blanchflower, "Discrimination in the Small-Business Credit Market," 942; Dymski, "Discrimination in the Credit and Housing Markets,"

9 \& 28; Kim, "Data-Driven Discrimination at Work," 857.

${ }^{13}$ Sullivan, "Who Benefits from Spam?"

${ }^{14}$ Lofters, "Sociodemographic Data Collection in Healthcare Settings," 197-198.

${ }^{15}$ Lupton, The Quantified Self.

${ }^{16}$ Lofters, "Sociodemographic Data Collection in Healthcare Settings," 197-198.

17 Joint United Nations Programme on HIV/AIDS, "Confronting Discrimination," 2.
} 
the world have recognised this concern by upholding robust protections for the right to privacy in one's HIV status. ${ }^{18}$ They have even blocked efforts by governments to create lists of children living with HIV for the purposes of public health outreach. ${ }^{19}$ Among other things, these cases demonstrate the role the law and courts can play in regulating health data through the protection of human rights.

In this work, we focus on a particular group of countries with high TB burdens (see Table 1) as identified by the WHO's 2019 Global Tuberculosis Report. These 14 countries appear on all three of the WHO's high TB burden lists, for drug-sensitive TB, multidrug-resistant TB and TB/HIV co-infection. These 14 nations alone make up 63.41 per cent of global TB burden, with 6.3 million cases of TB for the period of 2016-2020. ${ }^{20}$

Table 1: High Burden TB Countries and Estimates of TB Burden (in thousands)

\begin{tabular}{ccc}
\hline Country & Population & TB Estimate \\
\cline { 3 - 3 } \cline { 3 - 3 } Angola & 31,000 & 109 \\
China & $1,430,000$ & 866 \\
DR Congo & 84,000 & 270 \\
Ethiopia & 109,000 & 165 \\
India & $1,350,000$ & 2,690 \\
Indonesia & 268,000 & 845 \\
Kenya & 51,000 & 150 \\
Mozambique & 29,000 & 162 \\
Myanmar & 54,000 & 181 \\
Nigeria & 196,000 & 429 \\
Papua New Guinea & 9,000 & 37 \\
South Africa & 58,000 & 301 \\
Thailand & 69,000 & 106 \\
Zimbabwe & 14,000 & 30 \\
\hline
\end{tabular}

Source: Data from WHO, Global Tuberculosis Report.

In these countries, as well as in countries with low TB burdens, particular groups are more vulnerable to TB than others. According to the United Nations (UN) Stop TB Partnership, key and vulnerable populations for TB include the rural and urban poor, prisoners, mobile populations, children, miners, people living with HIV, people who use drugs, indigenous peoples and healthcare workers. ${ }^{21}$ People in these groups are more vulnerable to TB due to environmental risks, biological susceptibility, behavioural factors and/or limited access to TB prevention, testing and treatment services. ${ }^{22}$ People in these groups also experience other social, political and economic disadvantages, and they suffer from relatively high rates of TB even in wealthy countries like the United States.

\section{Data Neocolonialism}

Important considerations about data control occur at the intersections of agency and data ownership and surveillance. When individuals do not control their own private data, especially as it pertains to their health, they experience a loss of agency. Blurring the lines between volunteering data and data collected through mandatory surveillance, including for public health purposes, serves to commodify the human body as a data resource. This massive data collection infrastructure has

\footnotetext{
${ }^{18}$ X v. Y, [1988] 2 All ER 648 UK; Doe v. SEPTA, 72 F.3d 1133 (1995); NM v. Smith, [2007] ZACC 6.

${ }^{19}$ KELIN v. Cabinet Secretary-Ministry of Health, Petition 250 of 2015, High Court of Kenya at Nairobi.

${ }^{20}$ WHO, Global Tuberculosis Report, 24.

21 Stop TB Partnership, "Data for Action for Tuberculosis."

22 Stop TB Partnership, "Data for Action for Tuberculosis."
} 
transformative power in our globalised society. As explained by Olleros and Zhegu, 'a critical element of the transformative power of digital technologies is their rising capacity to datafy all aspects of life on this planet'. ${ }^{23}$

By considering colonialism as both an economic enterprise and a way of colonising knowledge, it is easy to see how data becomes a valuable resource. ${ }^{24}$ Data commodification can be traced to underlying systems of oppression and control using this extended metaphor to colonialism, particularly as the development of 'data regimes' emerge as uneven across the globe. ${ }^{25}$ In this way, data gathering is 'data colonialism through accumulation by dispossession', or the colonisation of digital and subsequently physical space by accumulating the data comprising the commodified individual. ${ }^{26}$ Importantly, many of the rules and regulations surrounding data collection and dissemination in these contexts are not generated within the postcolonial, Global South context. Instead, large multinational organisations, including private corporations based in the Global North, enter the digital arena and create structures of data gathering that affect people within the postcolonial space.

In other words, big data further exacerbates and entrenches postcolonial structures through the appropriation of an increasingly valuable resource - personal data. In their 2018 article about how data collection can constitute postcolonialism, Couldry and Mejias explain that 'we are often told that data are the new oil. But unlike oil, data are not a substance found in nature. It must be appropriated' ${ }^{27}$ Just as the labour and natural resources of indigenous populations were appropriated by colonial powers, the personal data of the people living in these postcolonial contexts is now being appropriated by private corporations, international organisations and their own governments through the collection of personal data, including health data through public health surveillance.

Notably, all but two of the high burden TB countries in Table 1 have a colonial legacy (see Table 2). These histories of social and political oppression, the appropriation of labour and natural resources, and cultural eradication cannot be ignored in an examination of contemporary data control and surveillance of TB key and vulnerable populations in these countries. This is particularly so as many of these countries are still characterised by deeply unequal social and economic structures rooted in their colonial histories. Even if we assume that the intentions to identify people with TB are made purely in good faith, to treat and cure them (for which there is evidence to the contrary ${ }^{28}$ ), the result is elevated data generation, control and surveillance of vulnerable people living in postcolonial contexts by national governments and multinational organisations.

We note here the recent coordination between the WHO and big tech companies in the WHO's effort to curb the spread of disinformation and falsehoods around the coronavirus outbreak in China, which has quickly become a global pandemic. The New York Times reports that a WHO social media officer and her colleagues had been in contact since the outbreak began with 'the world's biggest and most powerful disseminators of information', including Google, Facebook and Twitter, with plans to engage Amazon, Uber and Airbnb. ${ }^{29}$ While the aim to combat the spread of falsehoods and promote the dissemination of accurate information about the dangerous virus is critically important, the entanglement of the WHO and tech companies that produce and commodify massive amounts of personal data prompts at least two serious concerns. First, trusting big tech companies to fight the spread of falsehoods raises red flags given their involvement in disinformation campaigns during recent elections and in conflict zones around the world, and their use by authorities to suppress speech in authoritarian regimes. ${ }^{30}$ Second, there is a risk these relationships may transform from the spread of accurate information important for public health to the sharing of personal data among big tech companies and the WHO or national public health authorities, allowing for expanded public health surveillance and the production of enormous amounts of personal health data.

\footnotetext{
${ }^{23}$ Olleros, "Data Transformations," 3.

${ }^{24}$ Dourish, "Ubicomp's Colonial Impulse," 133.

25 Thatcher, "Data Colonialism Through Accumulation by Dispossession," 1000.

${ }^{26}$ Thatcher, "Data Colonialism Through Accumulation by Dispossession," 993.

${ }^{27}$ Couldry, "Data Colonialism," 336.

${ }^{28}$ Letter from Eugenia Fernan-Zegarra, Peruvian Ombudsman, Office of Public Defender of Peru, to Yuri Munoz Martinez, Executive Director, National Solidarity Assistance Programme (21 November, 2017); “Mburu, Detention of People Lost to Follow Up;” Peruvian Ombudsman, Office of Public Defender of Peru, Opinion on the Enjoyment of the Subsidy of the National Programme of Solidarity Assistance: Pension 65 Conditioned on the Adherence to the Treatment of TB, Informe de Adjuntia No 31-2017-DP/AAE (2017) (addressing the suspension and removal of elderly, poor people with TB who stop their treatment from receiving a public subsidy in the form of cash assistance under the Pension 65 Programme of the National Programme of Solidarity Assistance).

${ }^{29}$ Richtel, "W.H.O. Fights a Pandemic."

${ }^{30}$ Bradshaw, "Global Disinformation Order."
} 
Table 2: Colonial History of High TB Burden Countries

\begin{tabular}{|c|c|c|}
\hline Country & Colonial Powers & Year of Independence \\
\hline Angola & Portuguese & 1974 \\
\hline China & - & - \\
\hline DR Congo & Belgium & 1960 \\
\hline Ethiopia & Occupied by Italy & 1941 \\
\hline India & $\begin{array}{l}\text { Dutch, Danish, French, } \\
\text { Portuguese, British }\end{array}$ & 1947 \\
\hline Indonesia & $\begin{array}{c}\text { Portuguese, Dutch, } \\
\text { French/British, Netherlands }\end{array}$ & 1949 \\
\hline Kenya & British & 1964 \\
\hline Mozambique & Portuguese & 1975 \\
\hline Myanmar & British & 1948 \\
\hline Nigeria & British & 1960 \\
\hline Papua New Guinea & British, Dutch, Australians & 1975 \\
\hline South Africa & Dutch, British & 1961 \\
\hline Thailand & - & - \\
\hline Zimbabwe & British & 1980 \\
\hline
\end{tabular}

\section{Active Case Finding and Digital Adherence Technologies}

To more concretely examine the unique risks tied to data in the global TB response, we define and illustrate data risks and human rights concerns associated with two key interventions: ACF and DATs. First, we describe these two strategies and consider their effectiveness and related concerns. Next, we present the normative and legal content of a set of human rights critical to the TB response, highlighting how each right implicates the production and use of personal health data. Finally, we apply these human rights to ACF and DATs to highlight the threats they pose to the human rights of people affected by TB.

\section{Active Case Finding}

The recent mantra of the global TB response is to 'Find the Missing Millions' ${ }^{31}$ Around 10 million people per year contract $\mathrm{TB}$, but only 6 million are identified. The remaining 4 million are the so-called missing millions. ${ }^{32}$ In theory, finding people affected by TB is good for everyone, as people who have been identified can start treatment, receive counselling and stop spreading the disease.

Efforts to identify the 'missing millions' are being intensified in the midst of a paradigm shift from 'passive' to 'active' case finding. ACF is often referred to as 'systematic screening', an organised process initiated by healthcare providers to identify

\footnotetext{
${ }^{31}$ Chin, "Finding the Missing Tuberculosis Patients," S675.

32 WHO, Global Tuberculosis Report.
} 
people with TB outside health facilities. This is in contrast to 'passive case finding' in which people who are sick seek medical attention at a health facility and are then diagnosed with TB. This means that public health systems in high burden TB countries are proactively working to identify, test and treat millions of people with TB. The WHO has advised against mass screening for TB for decades, so for now ACF is only recommended for use for TB key and vulnerable populations. ${ }^{33}$ These populations, as noted above, comprise socially, economically and culturally disadvantaged groups in all the countries where they are found. As a result, through ACF, public health authorities are collecting, storing and eventually processing massive amounts of data on millions of vulnerable people affected TB, as well as the communities where they must be found.

In light of this, we highlight that public health initiatives often create government records or even spread information throughout communities in the name of protecting populations. For example, in Kenya, lists were kept by the President's office that identified children living with HIV. ${ }^{34}$ Under the auspices of public health, compromising personal health information like this may be exposed and distributed beyond individuals and their medical advisers. Even when data is not intentionally curated or spread, finding and identifying people inherently generates data and creates risk.

\section{DOT v. DAT}

The dominant treatment paradigm for TB since the early 1990s is Directly Observed Therapy (DOT). The strong form of DOT requires people with TB to go to a health facility so a healthcare worker may observe them take their medication, particularly during the two-month intensive phase of the six to ninth months treatment. Facility-based DOT causes social and economic hardships for people with TB, including costs associated with travelling to a clinic, income or employment loss due to missed work, stigma and discrimination from recurring visits to a TB clinic, and the paternalism and lack of respect for autonomy inherent in the DOT approach. ${ }^{35}$ Moreover, evidence indicates DOT does not improve adherence to TB treatment or treatment success rates. ${ }^{36}$ The dominance of DOT has also come with an opportunity cost. The myopic, global focus on the DOT strategy overlooks and de-prioritises other alternatives that may better promote treatment adherence and success through, for instance, treatment literacy. As a result, there is a lack of treatment options that respect and promote the agency of people with TB, involving them in health decision-making processes and providing them with comprehensive and accurate information about TB and its treatment.

In an effort to solve these problems, a paradigm shift is underway in TB treatment using DATs. In the TB context, DATs often entail ingestion of TB medication with some sort of digital prompting or monitoring. Practically speaking, this means that people with TB need not go to a health facility every day to take their medication. Instead, they might film a video or be watched in real time taking their medicine by a healthcare worker by streaming a video from their phone. DATs also include ingestible electronic sensors that collect and send digital information about a person's treatment to health authorities.

While DATs may alleviate the disadvantages caused by requiring people with TB to travel to health facilities simply to take their medicine, they result in the production of a digital data record of their treatment, including whether and how they have complied with the treatment during the six to nine months regimen. Table 3 (below) lays out a variety of DATs being considered or currently used for TB treatment, using the classification scheme outlined in recent meta-analyses of TB treatment strategies. ${ }^{37}$ The table also notes the inconsistent evidence demonstrating that DATs are not necessarily any more effective than traditional DOT in promoting treatment adherence and improved treatment outcomes.

\footnotetext{
${ }^{33}$ Stop TB Partnership, "Stop TB Field Guide 1.”; WHO, "Systematic Screening for Active Tuberculosis," 1-2.

${ }^{34}$ KELIN v. Cabinet Secretary-Ministry of Health, High Court of Kenya at Nairobi, [2016] eKLR Petition 250 of 2015.

35 TB Care I, "International Standards for Tuberculosis Care," 39; Gebremariam, "Barriers and Facilitators of Adherence to TB Treatment," 5.

${ }^{36}$ Pasipanodya, "Meta-Analysis of Self-Administered vs Directly Observed Therapy," 28; Volmink, "Directly Observed Therapy for Treating Tuberculosis," 5.

${ }^{37}$ Ngwatu, "Impact of Digital Health Technologies on Tuberculosis Treatment."
} 
Table 3: Directly Observed Therapy (DOT) v. Digital Adherence Technology (DAT)

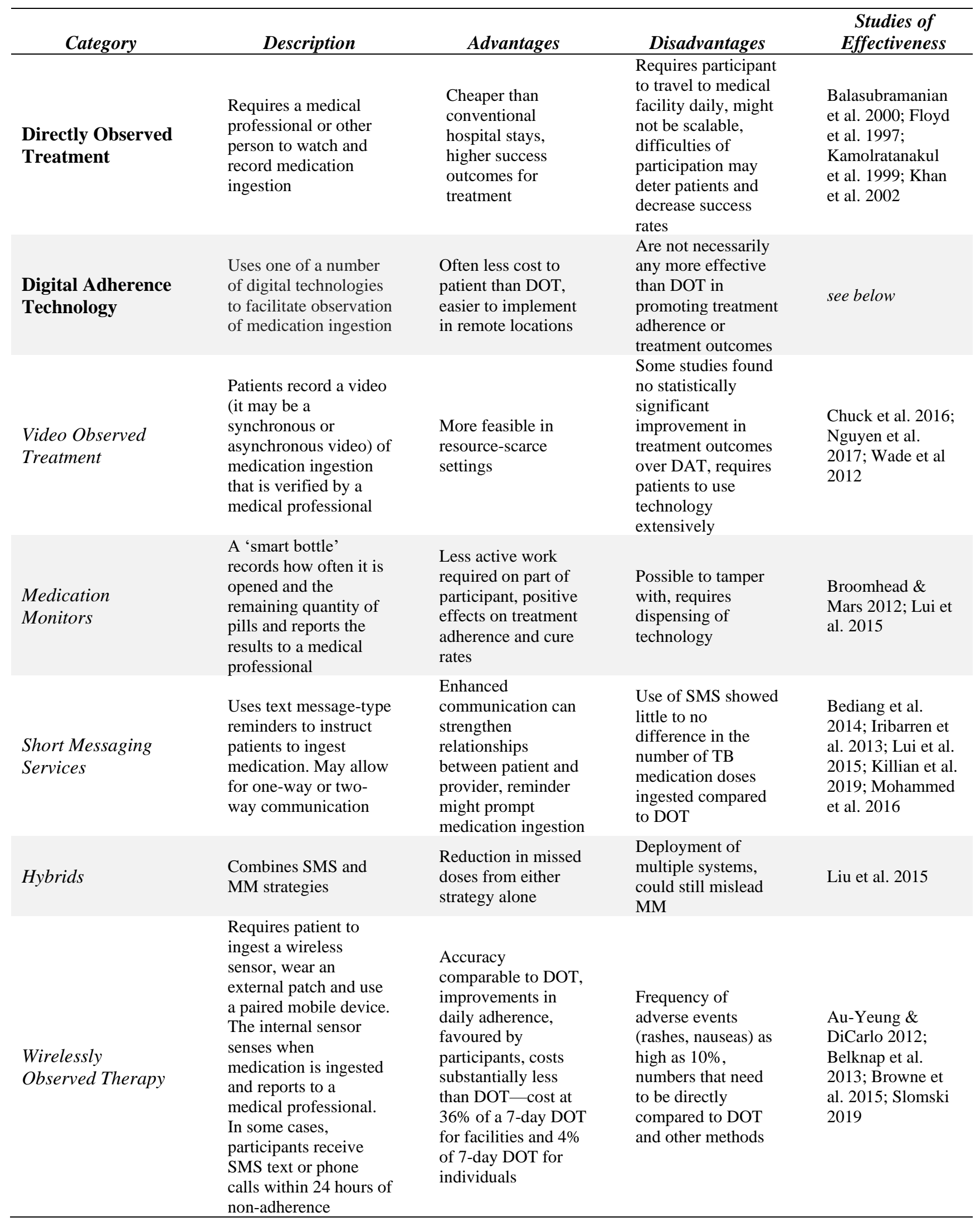


Rather than a truly unique alternative to DOT, DATs represent a trojan horse. They purport to offer a new, more effective treatment paradigm, but they essentially dress up DOT in new digital clothes while producing enormous amounts of data on the people with TB who use them. These new types of data records are characterised by heavy surveillance via video records, digital trace records and ingestible sensors. As the use of DATs has been scaled up, so has the use of progressively more intrusive technologies. ${ }^{38}$ Wirelessly Observed Therapy is the clearest example of this. For these technologies to work, patients have to swallow a device that collects data on their actions while it sits inside their bodies. If used for a large number of patients, the end result of Wirelessly Observed Therapy would be widespread electronic monitoring of a whole range of patient behaviour, not simply whether they are complying with their TB treatment.

DATs also encompass a broader array of approaches to TB treatment, beyond video or physical medication ingestion. In the case of a new technology called One Impact, a fully functioning phone application helps individuals manage their own treatment, and also helps them find support groups and build support systems. ${ }^{39}$ This more holistic approach to using digital technology to improve treatment adherence and outcomes is laudable. However, there is currently insufficient information available about what happens to the data generated within the application, including how and where it will be stored, who will have access to it, and why and what security protocols will be used throughout the electronic network.

\section{Human Rights}

In 1948, in the aftermath of the Second World War, a diverse range of experts came together to author the UN Declaration of Human Rights. ${ }^{40}$ While the originators of this document did not necessarily agree on the philosophical underpinnings of the Declaration or its substantive content, they did come to consensus on the universality of human rights. ${ }^{41}$ As a result, human rights represent a global consensus with great normative power, but they are also legitimated in law at international, regional and national levels. For example, the rights in the UN Declaration of Human Rights were later codified under international law in a series of treaties, most importantly the International Covenant on Civil and Political Rights (ICCPR) and the International Covenant on Economic, Social and Cultural Rights (ICESCR). Moreover, all the national constitutions in the world include sets of these international human rights, sometimes employing the same language and interpretations. And, as Table 4 demonstrates, the human rights we highlight in this section as especially important for the TB response are, by and large, enshrined in the national constitutions of the WHO high TB burden countries listed in Table 1.

Human rights and their content, therefore, provide an action-guiding tool for reform borne of international law and global consensus, including in big data and TB. In the context of the global TB response, recently, the Declaration of the Rights of People Affected by Tuberculosis, sponsored by the UN Stop TB Partnership, clearly links international human rights to the fight against TB. The Declaration comprises a list of human rights contextualised for TB and claimed by people affected by TB around the world through the document. ${ }^{42}$ In the context of health data, the UN Special Rapporteur on the Right to Privacy recently published a series of recommendations for the protection and use of health-related data. ${ }^{43}$ They include detailed guidance based on human rights law for, among other things, health-related data in the context of intersectionality, gender and people living with disabilities, mobile devices and systems, artificial intelligence, health-related algorithms, data breaches and big data.

\footnotetext{
${ }^{38}$ See studies cited in Table 3; WHO, "Handbook for the Use of Digital Technologies to Support Tuberculosis Medication Adherence."

39 One Impact, "Stop TB Partnership: One Impact."

${ }^{40}$ UN General Assembly. UN Declaration of Human Rights.

${ }^{41}$ Beitz, "What Human Rights Mean," 36.

${ }^{42}$ Declaration of the Rights of People Affected by Tuberculosis, Stop TB Partnership and TB People (June 2019).

${ }^{43}$ Explanatory Memorandum to the Recommendation on the Protection and Use of Health-Related Data, Mandate of the United Nations Special Rapporteur on the Right to Privacy, Task Force on Privacy and the Protection of Health-Related Data (4 October, 2019);

Recommendation on the Protection and Use of Health-Related Data, Mandate of the United Nations Special Rapporteur on the Right to Privacy, Task Force on Privacy and the Protection of Health-Related Data (5 December, 2019).
} 
Table 4: Matrix of Human Rights in Constitutions in High TB Burden Countries

Human Rights Enshrined in National Constitutions

\begin{tabular}{|c|c|c|c|c|c|c|c|c|}
\hline Country & Health & Privacy & Confidential. & $\begin{array}{c}\text { Informed } \\
\text { Consent }\end{array}$ & $\begin{array}{c}\text { Bodily } \\
\text { Integrity }\end{array}$ & Information & $\begin{array}{c}\text { Non- } \\
\text { discrim. }\end{array}$ & Liberty \\
\hline Angola & $\mathrm{X}$ & $\mathrm{x}$ & & & $\mathrm{x}$ & & $\mathrm{x}$ & $\mathrm{x}$ \\
\hline China & & $\mathrm{x}$ & & & & & & $\mathrm{x}$ \\
\hline DR Congo & $\mathrm{x}$ & $\mathrm{x}$ & & & $\mathrm{x}$ & $\mathrm{x}$ & $\mathrm{x}$ & $\mathrm{x}$ \\
\hline Ethiopia & $\mathrm{x}$ & $\mathrm{x}$ & & & & $\mathrm{x}$ & $\mathrm{x}$ & $\mathrm{x}$ \\
\hline India & $\mathrm{x}$ & & & & & & $\mathrm{x}$ & $\mathrm{x}$ \\
\hline Indonesia & $\mathrm{x}$ & & & & & $\mathrm{x}$ & $\mathrm{x}$ & \\
\hline Kenya & $\mathrm{x}$ & $\mathrm{x}$ & & & & $\mathrm{x}$ & $\mathrm{x}$ & $\mathrm{x}$ \\
\hline Mozambique & $\mathrm{x}$ & $\mathrm{x}$ & & & $\mathrm{x}$ & $\mathrm{x}$ & $\mathrm{x}$ & $\mathrm{x}$ \\
\hline Myanmar & $\mathrm{x}$ & $\mathrm{x}$ & & & & & $\mathrm{x}$ & $\mathrm{x}$ \\
\hline Nigeria & $\mathrm{x}$ & $\mathrm{x}$ & & & & $\mathrm{x}$ & $\mathrm{x}$ & $\mathrm{x}$ \\
\hline $\begin{array}{l}\text { Papua New } \\
\text { Guinea }\end{array}$ & $\mathrm{x}$ & $\mathrm{x}$ & & & & $\mathrm{x}$ & & \\
\hline South Africa & $\mathrm{x}$ & $\mathrm{x}$ & & $\mathrm{x}$ & $\mathrm{x}$ & $\mathrm{x}$ & $\mathrm{x}$ & \\
\hline Thailand & $\mathrm{x}$ & $\mathrm{x}$ & $\mathrm{x}$ & & & $\mathrm{x}$ & & $\mathrm{x}$ \\
\hline Zimbabwe & $\mathrm{x}$ & $\mathrm{x}$ & & $\mathrm{x}$ & $\mathrm{x}$ & $\mathrm{x}$ & $\mathrm{x}$ & $\mathrm{x}$ \\
\hline
\end{tabular}

Notes: Right to health is enshrined as a right to healthcare.

Here, we present the definition and content of the right to health and its dimensions protecting physical integrity and informed consent. Next, we consider right to privacy and confidentiality. We then examine the right of people affected by TB to be free from discrimination. Finally, we consider the role of the right to liberty in protecting people with TB from being deprived of their liberty in the name of public health. For each right, we highlight relevant implications for the use of big data in the TB response.

\section{The Right to Health}

The right to health provides an important frame for considering the relationship between health systems, the TB epidemic and data generation associated with people affected by TB. The right to health and its various components establish a system of health rights based on and extending the reach of medical ethics and norms. The right broadly requires governments to not only ensure access to good-quality TB services, but also to respect the privacy and confidentiality of people affected by the disease. In particular, the right to health established in article 12 of the ICESCR includes the right to have personal health data treated 
with confidentiality, and it establishes a core obligation of governments to ensure all health facilities, goods and services are designed to respect confidentiality. ${ }^{44}$ Guaranteeing informed consent is also a fundamental dimension of the right to health and requires that public health measures, including TB surveillance, strive for voluntary participation to be fully effective and to protect privacy. The UN Special Rapporteur on the Right to Health has explained that informed consent is particularly important for vulnerable groups, including women, ethnic minorities, indigenous populations and people living with HIV. ${ }^{45}$ The right to physical integrity is also a component of the right to health and establishes the negative corollary of the right to informed consent - the right to be free from non-consensual medical treatment and experimentation.

\section{The Right to Privacy}

The right to privacy in article 17 of the ICCPR includes the right to keep personal information, including personal health information private. The right to privacy includes the right to confidentiality in healthcare and other health-related settings for people affected by TB, including during the collection, storage and processing of health data. However, the universe of privacy is more expansive. While confidentiality characterises the relationship between patients and healthcare workers, privacy extends to the world and community surrounding the patient. The right to privacy can, therefore, be logically extended to protect not only the person, but the data representations of that person.

According to the UN Special Rapporteur on the Right to Privacy, States have an obligation to regulate by law the collection and electronic processing, storage, transmission and disposal of personal information, whether by public or private individuals or institutions. This regulation must ensure, among other things: that information about a person's private life is not accessed or received by people who are not authorised by law to receive, process or use it; that personal information is never used for purposes incompatible with international human rights law; and that people have the right to delete or erase personal data and rectify incorrect personal information. ${ }^{46}$

\section{The Right to be Free from Discrimination}

Stigmatisation and discrimination against people affected by TB occurs in healthcare settings, employment, education, housing and the family, among other places. The right to be free from discrimination, enshrined in the ICCPR, the ICESCR and other international treaties, prohibits both direct and indirect discrimination against people with $\mathrm{TB}$, TB survivors and their associates based on health status, whether perceived or actual. Protection from discrimination requires that sensitive personal health data not be shared beyond those involved in the healthcare of people affected by TB without the person's consent to prevent the data's misuse or abuse.

Data breaches resulting in the leaking or unauthorised use of personal health data of people affected by TB may lead to stigma and discrimination. The collection of TB-related data by public health authorities, healthcare providers and others in the community, such as in homes, at schools or at workplaces, also risks signalling to community members, family, friends, classmates or co-workers - correctly or incorrectly - that certain people, households or entire communities are affected by TB. Given the intensity of TB-related stigma and discrimination, the disclosure of TB-related personal data or the signalling that someone may have TB can lead to grave social and economic consequences. For example, in Peru, regulations implementing national TB legislation allow for the removal of people with TB who are found to have stopped or interrupted treatment from a pension programme for the elderly and the poor. ${ }^{47}$ Similarly, in Mumbai, India, people who interrupt or stop TB treatment can lose access to a public food assistance programme. ${ }^{48}$

\footnotetext{
${ }^{44}$ Committee on Economic, Social and Cultural Rights, General Comment No 14, UN Doc E/C.12/2000/4 (11 August, 2000)

${ }^{45}$ Report of United Nations Special Rapporteur on the Right of Everyone to the Enjoyment of the Highest Attainable Standard of Physical and Mental Health to the General Assembly on informed consent, UN Doc A/64/272 (Aug. 10, 2009).

${ }^{46}$ United Nations Special Rapporteur, Draft Recommendation on the Protection and Use of Health-Related Data.

${ }^{47}$ Letter from Eugenia Fernan-Zegarra, Peruvian Ombudsman, Office of Public Defender of Peru, to Yuri Munoz Martinez, Executive Director, National Solidarity Assistance Programme (21 November, 2017); Peruvian Ombudsman, Office of Public Defender of Peru, Opinion on the Enjoyment of the Subsidy of the National Programme of Solidarity Assistance: Pension 65 Conditioned on the Adherence to the Treatment of TB, Informe de Adjuntia No 31-2017-DP/AAE (2017) (addressing the suspension and removal of elderly, poor people with TB who stop their treatment from receiving a public subsidy in the form of cash assistance under the Pension 65 Programme of the National Programme of Solidarity Assistance).

${ }^{48}$ Mahesh, "Coercion in the TB Response." On file with the authors.
} 


\section{The Right to Liberty and Security of Person}

The right to liberty and security of person in article 9 of the ICCPR protects people affected by TB from arbitrary detention. This includes punitive or coercive detention or imprisonment of people with TB for interrupting or stopping their treatment. Involuntary isolation of people with TB is justifiable in extremely narrow circumstances when, among other things, a person with TB is actively contagious, poses a real risk of disease transmission to other people and is unwilling or unable to initiate treatment or implement infection control measures. ${ }^{49}$ Despite this, people with TB are detained, imprisoned and isolated against their will in violation of their right to liberty and security of person. ${ }^{50}$ Data breaches or the misuse of health data of people affected by TB in these contexts are particularly dangerous, as they may lead to arbitrary detention and violations of the right to liberty and security of person.

\section{Human Rights Risks for the Use of Data in Active Case Finding and Digital Adherence Technologies for TB}

Here, we demonstrate the relationship between human rights and data production using the two case studies introduced above for ACF and DATs. For both, it is critical to note that, while TB is an airborne infectious disease, people with TB are no longer contagious after two to three weeks of appropriate treatment, sometimes sooner. This is important because legitimate concerns about disease transmission are no longer relevant after the period of contagiousness is over.

\section{Human Rights Risks for Active Case Finding}

The production of big data through ACF to find the missing millions poses serious risks to the human rights of people affected by TB. The Stop TB Partnership acknowledges this in their Field Guide on case finding with key populations, explaining that 'even the most well-managed TB case-finding interventions will not succeed if they do not consider structural and [human] rights-related barriers'. ${ }^{1}$ The manner in which ACF is done, particularly in vulnerable communities, may violate the rights to informed consent and physical integrity, as parts of the right to health and core principles of medical ethics. Finding TB cases involves, in essence, identifying people at risk of TB infection or active TB disease to test them. Ensuring truly informed consent in these situations is difficult given the objective to find and test as many people as possible, and the information asymmetry around TB that exists between authorities conducting the intervention and the community members. As a result, testing for TB infection or TB disease, including the collection of sputum samples, may not always be done voluntarily based on informed consent.

Data collection during ACF also threatens the rights to privacy and confidentiality and, in turn, to be free from discrimination. ACF conducted in communities, in homes, at schools or at workplaces risks signalling to community members, family, friends, classmates or co-workers - correctly or incorrectly - that certain people, households or entire communities are affected by TB. ${ }^{52}$ In particular, the clothes, equipment or vehicles of the authorities collecting data may reveal they are testing for TB. Especially in poor communities, ACF can often mean unfettered access to people's homes for the purpose of public health surveillance. $^{53}$

Data breaches during the storage, transfer and processing of data collected during ACF also pose threats to the rights to privacy and confidentiality, particularly if effective security protocols are not in place and if personal data is not adequately deidentified. The non-consensual disclosure of private information about a person's TB status during the collection, storage, transfer or processing of data collected during ACF constitutes a violation of the rights to privacy and confidentiality. Non-consensual disclosures also carry the risk of serious social and economic consequences given the intensity of TB-related stigma and discrimination against people affected by TB in employment, housing, education, healthcare and the family. The effect of TBrelated stigma and discrimination is especially damaging for women. Women are often more vulnerable to TB-related stigma,

\footnotetext{
${ }^{49}$ Declaration of the Rights of People Affected by TB OR WHO, Ethics Guidance for the Implementation of the End TB Strategy (March 2017); UN Commission on Human Rights, The Siracusa Principles on the Limitation and Derogation Provisions in the International Covenant on Civil and Political Rights, (1984).

${ }^{50}$ Boggio, "Limitations on Human Rights," 122; Denholm, "Attitudes Towards Involuntary Incarceration for Tuberculosis," 155.

${ }^{51}$ Stop TB Partnership, "Stop TB Field Guide 1," 24.

${ }^{52}$ Stop TB Partnership, "Stop TB Field Guide 6," 30.

${ }^{53}$ Mahesh, "Coercion in the TB Response." On file with the authors.
} 
they may experience stigma at higher rates than men and they experience more severe effects to their family life as a result of TB-related stigma. ${ }^{54}$

Moreover, the fear of stigma and discrimination among people affected by TB can act as a deterrent to health-seeking behaviour, infringing the right to health. TB-related stigma and discrimination can delay or even prevent a timely and accurate TB diagnosis and the start of treatment among people affected by TB. Stigmatising and discriminatory treatment also hinders treatment adherence and completion among people with TB. ${ }^{55}$

\section{Human Rights Risks for Digital Adherence Technologies}

The production, storage and processing of personal data from people with TB through the use of DATs poses serious risks to human rights. These risks take shape in considering two primary concerns. The first concern is around the amount and nature of the data collected by DATs. The use of DATs will produce enormous amounts of digital data about people with TB, in the primary forms of videos, SMS messages and even statistical information about their bodily functions. All this data, in turn, will provide secondary data about whether and how people are complying with their treatment, but also about sensitive information, sometimes gathered incidentally, about where they live, who they associate with, where they travel day-to-day and a myriad of information about their bodies and bodily functions. The second concern, in light of the first, is about data breaches. That is, all the sensitive data collected by DATs must be securely stored to be processed and transferred by public health authorities. However, as most big data holders and producers will note, even with state-of-the-art technology and security protocols, the concern around a breach in the data-intentional or otherwise - is not if there will be a breach, but when. Even under the best circumstances, then, the rights to privacy and confidentiality in personal health data will be increasingly threatened by the scaleup of DATs due to the amount of data collected and the certainty of data breaches.

Data breaches resulting in the dissemination of sensitive personal data to unauthorised government officials or non-state actors may result in discrimination against people affected by TB based on their health status in the same ways noted above in the context of ACF. People with TB, or even TB survivors who have successfully completed treatment but remain in databases of information collected by DATs, may lose their employment, education or housing, and they may face stigma and social exclusion in the families and communities. Even without a breach, the data collected by DATs may be used and misused by government authorities to discriminate against people with TB who have not fully complied with their treatment regimen. As noted above, in Peru, people with TB who interrupt or stop their treatment are placed on a 'defaulters list' and are removed from public assistance for the poor and elderly under the Pension 65 Programme of the National Programme of Solidarity Assistance. ${ }^{56}$ Also noted above, in Mumbai, India, people with TB who interrupt or stop their treatment may lose access to a public food assistance programme for the poor. ${ }^{57}$ In China, people with TB are disqualified from working in government as part of the civil service until one to two years after they have completed treatment, even though they are not contagious after just a few weeks of treatment. ${ }^{58}$

In addition to discrimination, people with TB who stop or interrupt treatment may be arbitrarily detained, involuntarily isolated or even imprisoned in violation of their right to liberty and security of person. ${ }^{59}$ As explained above, involuntary isolation is only rarely permissible under very narrow and specific circumstances. The production and storage of increasingly large amounts of data through the use of DATs will likely increase the misuse of detention and involuntary isolation of people with TB who interrupt or stop their treatment. Moreover, in contexts in which people with TB from disadvantaged groups are targeted for

\footnotetext{
${ }^{54}$ Baral, "Causes of Stigma and Discrimination Associated with Tuberculosis," Cremers, "Assessing the Consequences of Stigma," 3; Courtwright, "Tuberculosis and Stigmatization," 36.

55 Chimbatata, "Post-2015, Why Delay to Seek Healthcare?" 3; Dodor, "The Feelings and Experiences of Patients," 213.

${ }^{56}$ Letter from Eugenia Fernan-Zegarra, Peruvian Ombudsman, Office of Public Defender of Peru, to Yuri Munoz Martinez, Executive Director, National Solidarity Assistance Programme (21 November, 2017); Peruvian Ombudsman, Office of Public Defender of Peru, Opinion on the Enjoyment of the Subsidy of the National Programme of Solidarity Assistance: Pension 65 Conditioned on the Adherence to the Treatment of TB, Informe de Adjuntia No 31-2017-DP/AAE (2017) (addressing the suspension and removal of elderly, poor people with TB who stop their treatment from receiving a public subsidy in the form of cash assistance under the Pension 65 Programme of the National Programme of Solidarity Assistance).

${ }^{57}$ Mahesh, "Coercion in the TB Response." On file with the authors.

${ }^{58}$ General Civil Service Recruitment Examination Standards (Trial). China Art 4.

${ }^{59}$ Coker, "Detention and the Evolving Threat of Tuberculosis," 611; Mburu, "Detention of People Lost to Follow-up," 43; Weiler-Ravell,

"Compulsory Detention of Recalcitrant Tuberculosis Patients," 323.
} 
isolation at higher rates than others, the deprivation of their liberty may also amount to discrimination. ${ }^{60}$ These practices not only represent violations of the right to liberty and security or person, but they are counterproductive to their own public health ends of preventing the spread of disease. That is, the involuntary isolation of people with TB discourages health-seeking behaviour, as people fear seeking TB testing or treatment knowing they risk detention or even imprisonment if they fail to fully comply with their treatment.

\section{Conclusion}

We have outlined unique data risks and threats to human rights posed by the use of ACF and DATs in the response to the TB epidemic. These risks are situated in deeper structural concerns around data neocolonialism, particularly in high TB burden countries, and the recognition that people affected by TB often experience intersecting vulnerabilities as members of marginalised groups. However, we are not advocating against the use of ACF or DATs altogether. We recognise the unique and important contributions they represent to finding and treating the 'missing millions' with TB. Rather, in highlighting these concerns, we aim to promote a more robust, informed conversation for these and other strategies employed in the TB response.

In particular, as we demonstrated above in Table 4, most countries with high TB burdens have enshrined the human rights examined in this paper in their national constitutions. This means that these rights may be used as legal tools at the national level, through litigation and other means, to address human violations resulting from the use of ACF and DATs. However, constitutional rights also provide a concrete legal basis on which to engage public and private health institutions in constructive dialogue to improve the design and implementation of ACF and DATs. Employing the normative and legal content of the rights to health, privacy, non-discrimination and liberty to better understand the effect these strategies have on people affected by TB provides a way forward to improve their effectiveness while ensuring they do not harm the people they aim to help.

As the global TB response continues to produce massive amounts of personal health data from vulnerable and marginalised groups through ACF, DATs and other interventions, it is crucial to understand the socio-historical contexts and the risks posed to the human rights of people affected by TB. We should not enter blindly into a new era of data colonisation and surveillance in the name of public health, nor should we dispose entirely of valuable innovations in the TB response because they pose legitimate risks. We must put people at the centre of the response through carefully considered interventions that leverage big data and human rights law in support of their health and well-being.

\section{Bibliography}

\section{Secondary Sources}

Arrieta-Ibarra, Imanol, Leonard Goff, Diego Jiménez-Hernández, Jaron Lanier and E. Glen Weyl. "Should We Treat Data as Labor? Moving beyond 'Free.'”AEA Papers and Proceedings, 108 (2018): 38-42.

Au-Yeung, K. Y. and L. DiCarlo. "Cost Comparison of Wirelessly vs. Directly Observed Therapy for Adherence Confirmation in Anti-Tuberculosis Treatment.” The International Journal of Tuberculosis and Lung Disease 16, no 11 (2012): 1498-1504. https://doi.org/10.5588/ijtld.11.0868

Balasubramanian, V. N., K. Oommen and R. D. O. T. Samuel. "DOT or Not? Direct Observation of Anti-Tuberculosis Treatment and Patient Outcomes, Kerala State, India." The International Journal of Tuberculosis and Lung Disease 4, no 5 (2000): 409-413.

Baral, Sushil C., Deepak K. Karki and James N. Newell. "Causes of Stigma and Discrimination Associated with Tuberculosis in Nepal: A Qualitative Study.” BMC Public Health 7, no 1 (2007). https://doi.org/10.1186/1471-2458-7-211

Bediang, Georges, Beat Stoll, Nadia Elia, Jean-Louis Abena, Désiré Nolna, Philippe Chastonay and Antoine Geissbuhler. "SMS Reminders to Improve the Tuberculosis Cure Rate in Developing Countries (TB-SMS Cameroon): A Protocol of a Randomised Control Study.” Trials 15, no 1 (2014): 35.

Beitz, Charles. "What Human Rights Mean.” Daedalus 132, no 1 (2003): 36-46.

\footnotetext{
${ }^{60}$ Coker, "Detention and the Evolving Threat of Tuberculosis," 611; Weiler-Ravell, "Compulsory Detention of Recalcitrant Tuberculosis Patients," 323.
} 
Belknap, Robert, Steve Weis, Andrew Brookens, Kit Yee Au-Yeung, Greg Moon, Lorenzo DiCarlo and Randall Reves. "Feasibility of an Ingestible Sensor-Based System for Monitoring Adherence to Tuberculosis Therapy." PloS One 8, no 1 (2013): e53373. https://doi.org/10.1371/journal.pone.0053373

Blanchflower, David G., Phillip B. Levine and David J. Zimmerman. "Discrimination in the Small-Business Credit Market.” Review of Economics and Statistics 85, no 4 (2003): 930-943. https://doi.org/10.1162/003465303772815835

Boggio, Andrea, Matteo Zignol, Emesto Jaramillo, Paul Nunn, Geneviève Pinet, and Mario Raviglione. "Limitations on Human Rights: Are they Justifiable to Reduce the Burden of TB in the Era of MDR-and XDR-TB?" Health and Human Rights (2008): 121-126.

Bradshaw, Samantha and Philip N. Howard. “The Global Disinformation Order: 2019 Global Inventory of Organised Social Media Manipulation." (Computational Propaganda Research Project, Oxford, UK, 2019).

Broomhead, Sean and Maurice Mars. "Retrospective Return on Investment Analysis of an Electronic Treatment Adherence Device Piloted in the Northern Cape Province." Telemedicine and e-Health 18, no 1 (2012): 24-31. https://doi.org/10.1089/tmj.2011.0143

Browne, S. H., R. Haubrich, K. Moser, A. Tucker, F. Vaida, C. Peloquin and C. Benson. "Wirelessly Observed Therapy (WOT): A New Paradigm in TB Therapy Monitoring." Conference on Retroviruses and Opportunistic Infections, Seattle/Washington, US, 23-26 February, 2015.

Chin, Daniel P. and Christy L. Hanson. "Finding the Missing Tuberculosis Patients." The Journal of Infectious Diseases 216, no suppl_7 (2017): S675-S678. https://doi.org/10.1093/infdis/jix368

Chimbatata, Nathan B. W., Chang-Ming Zhou, Chikondi M. Chimbatata and Biao Xu. "Post-2015, Why Delay to Seek Healthcare? Perceptions and Field Experiences from TB Healthcare Providers in Northern Malawi: A Qualitative Study." Infectious Diseases of Poverty 6, no 1 (2017): 60. https://doi.org/10.1186/s40249-017-0279-1

Chuck, C., E. Robinson, M. Macaraig, M. Alexander and J. Burzynski. "Enhancing Management of Tuberculosis Treatment with Video Directly Observed Therapy in New York City." The International Journal of Tuberculosis and Lung Disease 20, no 5 (2016): 588-593. https://doi.org/10.5588/ijtld.15.0738

Cohen, Adam, Victor Dahl Mathiasen, Thomas Schön and Christian Wejse. "The Global Prevalence of Latent Tuberculosis: A Systematic Review and Meta-Analysis.” European Respiratory Journal 54, no 3 (2019). https://doi.org/10.1183/13993003.00655-2019

Coker, Richard, Marianna Thomas, Karen Lock and Robyn Martin. "Detention and the Evolving Threat of Tuberculosis: Evidence, Ethics, and Law.” The Journal of Law, Medicine \& Ethics 35, no 4 (2007): 609-615. https://doi.org/10.1111/j.1748-720X.2007.00184.X

Cooper, Ashley. "Finding the Missing Millions Affected by Tuberculosis is One Thing; Treating Them is Another." The Lancet Respiratory Medicine (2019). https://doi.org/10.1016/S2213-2600(19)30196-1

Couldry, Nick and Ulises A. Mejias. "Data Colonialism: Rethinking Big Data's Relation to the Contemporary Subject." Television \& New Media 20, no 4 (2019): 336-349. https://doi.org/10.1177\%2F1527476418796632

Courtwright, Andrew and Abigail Norris Turner. "Tuberculosis and Stigmatization: Pathways and Interventions.” Public Health Reports 125, no 4 suppl (2010): 34-42. https://doi.org/10.1177/00333549101250S407

Center for Disease Control and Prevention. "U.S. Public Health Service Syphilis Study at Tuskegee." (Center for Disease Control and Prevention, Atlanta, Georgia, 2015).

Crawford, Kate, Mary L. Gray and Kate Miltner. "Critiquing Big Data: Politics, Ethics, Epistemology.” International Journal of Communication 8 (2014): 1663-1672.

Cremers, Anne Lia, Myrthe Manon de Laat, Nathan Kapata, Rene Gerrets, Kerstin Klipstein-Grobusch and Martin Peter Grobusch. "Assessing the Consequences of Stigma for Tuberculosis Patients in Urban Zambia." PloS One 10, no 3 (2015). https://doi.org/10.1371/journal.pone.0119861

Davis, Kord. Ethics of Big Data: Balancing Risk and Innovation. O’Reilly Media, 2012.

Denholm, J. T., J. J. Amon, R. O’Brien, A. Narain, S. J. Kim, A. El Sony and M. E. Edginton. “Attitudes Towards Involuntary Incarceration for Tuberculosis: A Survey of Union Members." The International Journal of Tuberculosis and Lung Disease 18, no 2 (2014): 155-159. https://doi.org/10.5588/ijtld.13.0609

Dodor, E. A. "The Feelings and Experiences of Patients with Tuberculosis in the Sekondi-Takoradi Metropolitan District: Implications for TB Control Efforts.” Ghana Medical Journal 46, no 4 (2012): 211.

Dourish, Paul and Scott D. Mainwaring. "Ubicomp's Colonial Impulse." Proceedings of the 2012 ACM Conference on Ubiquitous Computing, 133-142. Association for Computing Machinery: New York, NY, 2012.

Dymski, Gary A. "Discrimination in the Credit and Housing Markets: Findings and Challenges." Handbook on the Economics of Discrimination 215 (2006): 220.

Floyd, Katherine, David Wilkinson and Charles Gilks. "Comparison of Cost Effectiveness of Directly Observed Treatment (DOT) and Conventionally Delivered Treatment for Tuberculosis: Experience from Rural South Africa." BMI 315 , no 7120 (1997): 1407-1411. https://doi.org/10.1136/bmj.315.7120.1407 
Gebremariam, Mekdes K., Gunnar A. Bjune and Jan C. Frich. "Barriers and Facilitators of Adherence to TB Treatment in Patients on Concomitant TB and HIV Treatment: A Qualitative Study." BMC Public Health 10, no 1 (2010): 651. https://doi.org/10.1186/1471-2458-10-651

Iribarren, Sarah, Susan Beck, Patricia F. Pearce, Cristina Chirico, Mirta Etchevarria, Daniel Cardinale and Fernando Rubinstein. "TextTB: A Mixed Method Pilot Study Evaluating Acceptance, Feasibility, and Exploring Initial Efficacy of a Text Messaging Intervention to Support TB Treatment Adherence.” Tuberculosis Research and Treatment (2013). https://doi.org/10.1155/2013/349394

Joint United Nations Programme on HIV/AIDS. Confronting Discrimination Overcoming HIV-Related Stigma in Health Care Settings and Beyond. (Joint United Nations Programme on HIV/AIDS, 2017).

Kamolratanakul, Pirom, Holger Sawert, Somrat Lertmaharit, Yutichai Kasetjaroen, Somsak Akksilp, Chuchai Tulaporn, Kowit Punnachest, Sunan Na-Songkhla and Vallop Payanandana. "Randomized Controlled Trial of Directly Observed Treatment (DOT) for Patients with Pulmonary Tuberculosis In Thailand." Transactions of the Royal Society of Tropical Medicine and Hygiene 93, no 5 (1999): 552-557. https://doi.org/10.1016/S0035-9203(99)90379-6

Khan, M. A., J. D. Walley, S. N. Witter, A. Imran and N. Safdar. "Costs and Cost-Effectiveness of Different DOT Strategies for the Treatment of Tuberculosis in Pakistan." Health Policy and Planning 17, no 2 (2002): 178-186. https://doi.org/10.1093/heapol/17.2.178

Kaplan, Bonnie. "How Should Health Data Be Used?: Privacy, Secondary Use, and Big Data Sales." Cambridge Quarterly of Healthcare Ethics 25, no 2 (2016): 312-329. https://doi.org/10.1017/S0963180115000614

Killian, Jackson A., Bryan Wilder, Amit Sharma, Vinod Choudhary, Bistra Dilkina and Milind Tambe. "Learning to Prescribe Interventions for Tuberculosis Patients Using Digital Adherence Data." In Proceedings of the 25th ACM SIGKDD International Conference on Knowledge Discovery \& Data Mining, 2430-2438. Association for Computing Machinery: New York, NY, 2019.

Kim, Pauline T. "Data-Driven Discrimination at Work." William \& Mary Law Review. 58 no 3 (2016): 857.

Liu, Xiaoqiu, James J. Lewis, Hui Zhang, Wei Lu, Shun Zhang, Guilan Zheng, Liqiong Bai, Jun Li, Xue Li, Hongguang Chen, Mingming Liu, Rong Chen, Junying Chi, Jian Lu, Shitong Huan, Shiming Cheng, Lixia Wang, Shiwen Jiang, Daniel P. Chin and Katherine L. Fielding. "Effectiveness of Electronic Reminders to Improve Medication Adherence in Tuberculosis Patients: A Cluster-Randomised Trial." PLoS Medicine 12, no 9 (2015). https://dx.doi.org/10.1371\%2Fjournal.pmed.1001876

Lofters, Aisha K., Ketan Shankardass, Maritt Kirst and Carlos Quiñonez. "Sociodemographic Data Collection in Healthcare Settings: An Examination of Public Opinions." Medical Care (2011): 193-199. https://doi.org/10.1097/MLR.0b013e3181f81edb

Lupton, Deborah. The Quantified Self. Cambridge: John Wiley \& Sons, 2016.

Mahesh, Prabha. "Coercion in the TB Response: Stories from Community Work in Mumbai, India." 50th Union World Conference on Lung Health, Hyderabad, India, 2019.

Mburu, Gitau, Enrique Restoy, Evaline Kibuchi, Paula Holland and Anthony D. Harries. "Detention of People Lost to Follow-Up on TB Treatment in Kenya: The Need for Human Rights-Based Alternatives." Health and Human Rights 18 , no 1 (2016): 43.

Mohammed, Shama, Rachel Glennerster and Aamir J. Khan. "Impact of a Daily SMS Medication Reminder System on Tuberculosis Treatment Outcomes: A Randomized Controlled Trial.” PloS One 11, no. 11 (2016). https://doi.org/10.1371/journal.pone.0162944

Mom, Rommy. Guest Lecture at Northwestern University International Human Rights Clinic, 2019.

Moonan, Patrick K., Teresa N. Quitugua, Janice M. Pogoda, Gary Woo, Gerry Drewyer, Behzad Sahbazian, Denise Dunbar, Kenneth C. Jost, Charles Wallace and Stephen E. Weis. "Does Directly Observed Therapy (DOT) Reduce Drug Resistant Tuberculosis?" BMC Public Health 11, no 1 (2011): 19. https://doi.org/10.1186/1471-2458-11-19

Moonan, Patrick K., Sreenivas A. Nair, Reshu Agarwal, Vineet K. Chadha, Puneet K. Dewan, Umesh D. Gupta, Christine S. Ho, Timothy H. Holtz, Ajay M. Kumar, Nishant Kumar, Prahlad Kumar, Susan A. Maloney, Sundari R. Mase, John E. Oeltmann, C. N. Paramasivan, Malik M. Parmar, Kiran K. Rade, Ranjani Ramachandran, Raghuram Rao, Virendra S. Salhorta, Rohit Sarin, Sanjay Sarin, Kuldeep S. Sachdeva, Sriram Selvaraju, Rupak Singla, Diya Surie, Jamhoih Tonsing, Srikanth P. Tripathy and Sunil D. Khaparde. "Tuberculosis Preventive Treatment: The Next Chapter of Tuberculosis Elimination in India." BMJ Global Health 3, no. 5 (2018): e001135. https://dx.doi.org/10.1136\%2Fbmjgh-2018-001135

Nguyen, Thu Anh, Minh Tam Pham, Thi Loi Nguyen, Viet Nhung Nguyen, Duc Cuong Pham, Binh Hoa Nguyen and Greg James Fox. "Video Directly Observed Therapy to Support Adherence with Treatment for Tuberculosis in Vietnam: A Prospective Cohort Study.” International Journal of Infectious Diseases 65 (2017): 85-89. https://doi.org/10.1016/j.ijid.2017.09.029

Ngwatu, Brian Kermu, Ntwali Placide Nsengiyumva, Olivia Oxlade, Benjamin Mappin-Kasirer, Nhat Linh Nguyen, Ernesto Jaramillo, Dennis Falzon and Kevin Schwartzman. "The Impact of Digital Health Technologies on Tuberculosis Treatment: A Systematic Review.” European Respiratory Journal 51, no 1 (2018): 1701596. 
Olleros, F. Xavier and Majlinda Zhegu, eds. Research Handbook on Digital Transformations. Cheltenham: Edward Elgar Publishing, 2016.

One Impact. "Stop TB Partnership: One Impact." 2020. https://stoptbpartnershiponeimpact.org

Pasipanodya, Jotam G. and Tawanda Gumbo. "A Meta-Analysis of Self-Administered vs Directly Observed Therapy Effect on Microbiologic Failure, Relapse, and Acquired Drug Resistance in Tuberculosis Patients." Clinical Infectious Diseases 57, no 1 (2013): 21-31. https://dx.doi.org/10.1093\%2Fcid\%2Fcit167

Richtel, Matt. "WHO Fights a Pandemic Besides Coronavirus: An 'Infodemic.'” New York Times, February 6, 2020. https://www.nytimes.com/2020/02/06/health/coronavirus-misinformation-social-media.html

Stop TB Partnership. Stop TB Field Guide 6: Using Contact Investigation to Improve TB Case Detection. (Stop TB Partnership, 2018).

Stop TB Partnership. Stop TB Field Guide 1: TB Case Finding with Key Populations (Stop TB Partnership, 2018).

Stop TB Partnership. Data for Action for Tuberculosis Key, Vulnerable and Underserved Populations (Top TB Partnership, 2017).

Slomski, Anita. "Wireless Technology Quickly Confirms TB Medication Adherence.” Jama 322, no 24 (2019): $2375-2375$.

Story, Alistair, Richard S. Garfein, Andrew Hayward, Valiantsin Rusovich, Andrei Dadu, Viorel Soltan, Alexandru Oprunenco Kelly Collins, Rohit Sarin, Subhi Quraishi, Mukta Sharma, Giovanni Battista Migliori, Maithili Varadarajan and Dennis Falzon. "Monitoring Therapy Adherence of Tuberculosis Patients by Using Video-Enabled Electronic Devices." Emerging Infectious Diseases 22, no 3 (2016): 538. https://dx.doi.org/10.3201\%2Feid2203.151620

Subbaraman, Ramnath, Laura de Mondesert, Angella Musiimenta, Madhukar Pai, Kenneth H. Mayer, Beena E. Thomas and Jessica Haberer. "Digital Adherence Technologies for the Management of Tuberculosis Therapy: Mapping the Landscape and Research Priorities." BMJ Global Health 3, no. 5 (2018): e001018. https://doi.org/10.1136/bmjgh-2018-001018

Sullivan, Bob. "Who Profits from Spam? Surprise". MSNBC. http://www.nbcnews.com/id/3078642/print/1/displaymode/1098/

Tallon, Paul P. "Corporate Governance of Big Data: Perspectives on Value, Risk, and Cost.” Computer 46, no 6 (2013): $32-$ 38. https://doi.org/10.1109/MC.2013.155

TB CARE I. International Standards for Tuberculosis Care, 3rd ed. (The Hague, 2014).

Thatcher, Jim, David O'Sullivan and Dillon Mahmoudi. "Data Colonialism Through Accumulation by Dispossession: New Metaphors for Daily Data.” Environment and Planning D: Society and Space 34, no 6 (2016): 990-1006. https://doi.org/10.1177\%2F0263775816633195

Volmink, Jimmy and Paul Garner. "Directly Observed Therapy for Treating Tuberculosis.” Cochrane Database of Systematic Reviews 4 (2007). https://doi.org/10.1002/14651858.CD003343.pub4

Wade, Victoria A., Jonathan Karnon, Jaklin A. Eliott and Janet E. Hiller. "Home Videophones Improve Direct Observation in Tuberculosis Treatment: A Mixed Methods Evaluation.” PLoS One 7, no 11 (2012). https://doi.org/10.1371/journal.pone.0050155

Wandwalo, Eliud. 2019. “Q\&A: The Hunt for TB's 'Missing Millions.' "Voices. March 21, 2019. https://www.theglobalfund.org/en/blog/2019-03-21-qa-the-hunt-for-tb-missing-millions/

Weiler-Ravell, D., A. Leventhal, R. J. Coker and D. Chemtob. "Compulsory Detention of Recalcitrant Tuberculosis Patients in the Context of a New Tuberculosis Control Programme in Israel.” Public Health 118, no 5 (2004): 323-328. https://doi.org/10.1016/j.puhe.2003.10.005

WHO. Global Tuberculosis Report. (WHO, 2019).

WHO. Handbook for The Use of Digital Technologies to Support Tuberculosis Medication Adherence, No. WHO/HTM/TB/2017.30. (WHO, 2017).

WHO. Systematic Screening for Active Tuberculosis: Principles and Recommendations. No. WHO/HTM/TB/2013.04. (WHO, 2013).

\section{Court Cases}

KELIN v. Cabinet Secretary-Ministry of Health, High Court of Kenya at Nairobi, [2016] eKLR Petition 250 of 2015.

$X v . Y$, United Kingdom Court of Appeal, [1988] 2 All ER 648 UK.

Doe v. SEPTA, United States Court of Appeals, Third Circuit, 72 F.3d 1133 (1995).

NM v. Smith, Constitutional Court of South Africa, [2007] ZACC 6.

\section{Sources of Law and Legal Documents}

Committee on Economic, Social and Cultural Rights, General Comment No. 14, UN Doc E/C.12/2000/4 (2000).

Declaration of the Rights of People Affected by Tuberculosis, Stop TB Partnership and TB People (2019).

Explanatory Memorandum to the Recommendation on the Protection and Use of Health-Related Data, Mandate of the United Nations Special Rapporteur on the Right to Privacy, Task Force on Privacy and the Protection of Health-Related Data (2019). 
General Civil Service Recruitment Examination Standards (Trial). China Art 4 (2005).

Letter from Eugenia Fernan-Zegarra, Peruvian Ombudsman, Office of Public Defender of Peru, to Yuri Munoz Martinez, Executive Director, National Solidarity Assistance Programme (2017).

Peruvian Ombudsman, Office of Public Defender of Peru, Opinion on the Enjoyment of the Subsidy of the National Program of Solidarity Assistance: Pension 65 Conditioned on the Adherence to the Treatment of TB, Informe de Adjuntia, No 312017-DP/AAE (2017).

Recommendation on the Protection and Use of Health-Related Data, Mandate of the United Nations Special Rapporteur on the Right to Privacy, Task Force on Privacy and the Protection of Health-Related Data (2019).

Report of United Nations Special Rapporteur on the Right of Everyone to the Enjoyment of the Highest Attainable Standard of Physical and Mental Health to the General Assembly on Informed Consent, UN Doc A/64/272 (10 August, 2009).

UN Commission on Human Rights, The Siracusa Principles on the Limiation and Derogation Provisions in the International Covenant on Civil and Political Rights, E/CN.4/1984/4 (1984).

UN General Assembly. "Universal Declaration of Human Rights.” UN General Assembly 302, no 2 (1948).

UN Special Rapporteur. Draft Recommendation on the Protection and Use of Health-Related Data, OHCHR (2019). 